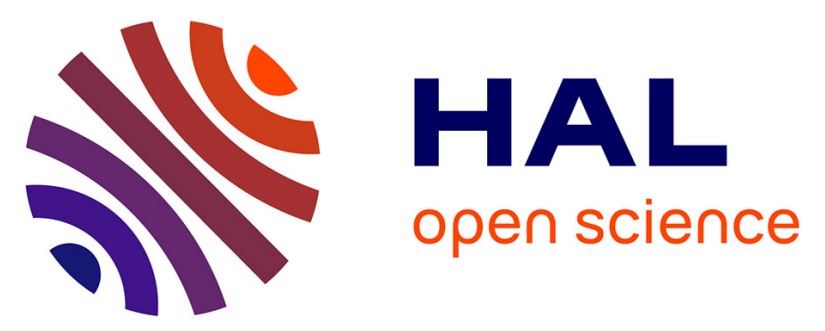

\title{
Lithiation of pure and methylated amorphous silicon: Monitoring by operando optical microscopy and ex situ atomic force microscopy
}

\author{
Yue Feng, Thuy-Doan-Trang Ngo, Marianthi Panagopoulou, Abdelhak \\ Cheriet, Bon Min Koo, Catherine Henry-De-Villeneuve, Michel Rosso, \\ Francois Ozanam
}

\section{To cite this version:}

Yue Feng, Thuy-Doan-Trang Ngo, Marianthi Panagopoulou, Abdelhak Cheriet, Bon Min Koo, et al.. Lithiation of pure and methylated amorphous silicon: Monitoring by operando optical microscopy and ex situ atomic force microscopy. Electrochimica Acta, 2019, 302, pp.249-258. 10.1016/j.electacta.2019.02.016 . hal-02380443

HAL Id: hal-02380443

https://hal.science/hal-02380443

Submitted on 22 Oct 2021

HAL is a multi-disciplinary open access archive for the deposit and dissemination of scientific research documents, whether they are published or not. The documents may come from teaching and research institutions in France or abroad, or from public or private research centers.
L'archive ouverte pluridisciplinaire HAL, est destinée au dépôt et à la diffusion de documents scientifiques de niveau recherche, publiés ou non, émanant des établissements d'enseignement et de recherche français ou étrangers, des laboratoires publics ou privés.

\section{(ㄷ)(1) $\$$}

Distributed under a Creative Commons Attribution - NonCommerciall 4.0 International 


\title{
Lithiation of pure and methylated amorphous silicon: monitoring by operando optical microscopy and ex situ atomic force microscopy
}

\author{
Yue Feng ${ }^{\mathrm{a}}$, Thuy-Doan-Trang Ngo ${ }^{\mathrm{a}}$, Marianthi Panagopoulou ${ }^{\mathrm{a}}$, Abdelhak Cheriet ${ }^{\mathrm{a}, \mathrm{b}, \mathrm{c}}$, Bon Min \\ $\mathrm{Koo}^{\mathrm{a}}$, Catherine Henry-de-Villeneuve ${ }^{\mathrm{a}}$, Michel Rosso ${ }^{\mathrm{a}}$, François Ozanam ${ }^{\mathrm{a}}$
}

a) Laboratoire de Physique de la Matière Condensée, Ecole Polytechnique, CNRS, Université Paris-Saclay, 91128 Palaiseau, France

b) CRTSE, Division Couches Minces Surfaces et Interfaces, 2 Bd Franz Fanon, BP 140 Alger 7-Merveilles 16038, Algeria

c) Faculty of sciences, Farhat Abbas University, Sétif 19000, Algeria

\section{Abstract}

Operando color microscopy and ex situ AFM were used to investigate the lithiation process in pure $(\mathrm{a}-\mathrm{Si}: \mathrm{H})$ and methylated $\left(\mathrm{a}-\mathrm{Si}_{1-\mathrm{x}}\left(\mathrm{CH}_{3}\right)_{\mathrm{x}}: \mathrm{H}\right)$ amorphous silicon thin layers. Color analysis of optical images allows for monitoring thickness changes of a-Si:H layers. Unlike pure a-Si:H, the first lithiation of a-Si $i_{1-x}\left(\mathrm{CH}_{3}\right)_{\mathrm{x}}: \mathrm{H}$ is found to be spatially non-uniform: lithiation starts at a limited number of locations then expands radially, forming circular lithiation spots. The morphology of the lithiation spots and their evolution is accurately measured by ex situ AFM. A mechanism is proposed to explain this phenomenon, involving the high resistivity of methylated silicon and the existence of low-resistance point defects.

\section{Introduction}

The most efficient solutions for high-density electrochemical energy storage are currently offered by lithium-ion batteries. However many applications still require an improvement of their energy density. Although it is not the main limiting factor, increasing the capacity of the negative electrode would increase this energy density. Silicon is one of the best anode materials, with a theoretical capacity ten times that of currently used carbon electrodes. However the use of silicon is severely limited due to the huge changes in volume associated with the lithium incorporation into and removing from the electrode [1].

Besides nanostructuration strategies which offer attracting possibilities for overcoming some of these limitations [2-4], another approach is to act on the material itself. Methylated amorphous silicon a-Si $i_{1-x}\left(\mathrm{CH}_{3}\right)_{\mathrm{x}}: \mathrm{H}$ [5] was shown to better sustain volume variations than standard amorphous silicon, thus improving the electrode cyclability. The origin of this improvement was attributed to 
two effects of the incorporation of methyl groups in the material: introduction of nano-voids and lowering of the reticulation degree of the silicon network.

It was recently reported that in methylated silicon, the first lithiation mechanism is similar to that observed in pure silicon [6]: in both materials the lithiation proceeds through a two-phase process, a lithium-rich phase $\mathrm{Li}_{\mathrm{z}} \mathrm{Si}$ with constant $\mathrm{Li}$ concentration progressively invading the unlithiated silicon. The lithium content $z$ of the invading phase was shown to depend on the methyl groups concentration $x$ : it decreases from 2.5 to 1 when $x$ increases from 0 to 0.05 , then increases almost linearly with $x$. At $x=0.1$, the lithium content is about 1.5 [6].

As the mechanical stress due to volume expansion of silicon during lithiation is the most important issue for the anode cyclability, a good understanding of this volume expansion is of prime interest. Operando TEM experiments gave precise measurements of this expansion for nanostructured a-Si [7, 8]. When fundamental understanding of the material intrinsic properties is sought for, performing a similar study on thin layers offers attracting possibilities: it should enable to obtain complementary information, because thin layers are particularly suitable for quantitative analysis of the lithiation mechanisms. They constitute a homogeneous medium, making operando observation achievable with a variety of experimental techniques, in particular surface characterization techniques.

In this paper, we focus on the first lithiation/delithiation cycle, more specifically on the first lithiation where the two-phase lithiation process is of prime importance for the evolution of the material during subsequent cycling, due to the high stress induced during this process. Our experiments take benefit from the fact that lithiation-induced volume changes of thin Si films induce thickness changes, which result in color change of the layer [9]. However color does not only depend on thickness, but also on optical properties of the material, which can depend on its composition. Hence the use of AFM, a technique only sensitive to the sample morphology is highly desirable. In situ AFM images of samples recorded during lithiation have already been reported [1016]. However, in situ AFM experiments are very delicate experiments as they must be performed in a glove box. Also, the time necessary to record a single image can be relatively long, especially when imaging large areas is necessary. This makes the monitoring of fast morphology changes difficult. We thus chose to perform ex situ AFM experiments on samples maintained in a stabilized state after lithiation, taking great care to choose a procedure allowing the sample to be kept in a state as close as possible to its state just after the electrochemical experiment. This sample stabilization also enabled to obtain a more general view of the sample, as it could be imaged in different locations and with various magnifications. 


\section{Experimental section}

\subsection{Preparation of amorphous silicon layers}

Amorphous Si layers were deposited by PECVD onto crystalline silicon (c-Si) or on polished stainless steel. The c-Si substrates were used for AFM experiments, and the stainless steel substrates for operando optical microscopy.

The c-Si substrates $\left(\sim 15 \times 15 \mathrm{~mm}^{2}\right.$ pieces, $500 \mu \mathrm{m}$ thick) were cut from (100) oriented, n-type, silicon wafers (one-side polished, float-zone purified, $\rho=1-100 \Omega \mathrm{cm}$, from Siltronix France). A gold layer (500 nm thick) was vacuum deposited on the rear unpolished face to ensure ohmic contact. The active layer was deposited on the front polished face.

Stainless steel substrates $\left(\sim 14 \times 14 \mathrm{~mm}^{2}\right.$ pieces, $1 \mathrm{~mm}$ thick $)$ were electropolished. The polishing mixture was composed of chromosulfuric acid $(11 \mathrm{~mL}), \mathrm{H}_{3} \mathrm{PO}_{4}(55 \mathrm{~mL})$ and ethanol $(\mathrm{EtOH})(60 \mathrm{~mL})$. It was stirred for $24 \mathrm{~h}$ before use. The stainless steel substrates were cleaned with acetone, rinsed with water and ethanol prior to their immersion (without drying) into the polishing solution. The electrochemical polishing was carried out at $65^{\circ} \mathrm{C}$ in a two-electrode electrochemical cell. After a 3 min polarization of the sample at $4.5 \mathrm{~V}$, polishing was carried out by applying $3.82 \mathrm{~V}$ for $30 \mathrm{~min}$. After polishing, the stainless steel substrates were rinsed with water, etched in $5 \% \mathrm{HF}$ for $10 \mathrm{~s}$, rinsed again with water and finally blown dry under nitrogen flow.

Pure a-Si:H and a-Si $i_{1-\mathrm{x}}\left(\mathrm{CH}_{3}\right)_{\mathrm{x}}: \mathrm{H}$ layers were prepared by radio-frequency Plasma-Enhanced Chemical Vapor Deposition (PECVD). Silane $\left(\mathrm{SiH}_{4}\right)$ or silane/methane mixture was used as precursor gas. a-Si $i_{1-\mathrm{x}}\left(\mathrm{CH}_{3}\right)_{\mathrm{x}}: \mathrm{H}$ layers were prepared using a low-power regime plasma (power $\mathrm{P}<$ $0.3 \mathrm{~W} \mathrm{~cm}^{-2}$ ) and low $\mathrm{CH}_{4}$ partial pressure $[17,18]$. In these conditions, only $\mathrm{SiH}_{4}$ molecules are directly decomposed (not $\mathrm{CH}_{4}$ molecules) and carbon incorporation into the amorphous $\mathrm{Si}$ layer is restricted to insertion of $\mathrm{CH}_{3}$ methyl groups.

Before layer deposition, the polished stainless steel substrates were submitted during 10 min to hydrogen $\left(\mathrm{H}_{2}\right)$ plasma in the PECVD chamber. The c-Si surfaces were deoxidized by immersion in a $5 \% \mathrm{HF}$ aqueous solution for $\sim 15 \mathrm{~s}$ just prior to their introduction into the PECVD chamber.

During deposition the substrates were heated at $250^{\circ} \mathrm{C}$. The excitation frequency and power, and the pressure during deposition were $13.56 \mathrm{MHz}, 0.10 \mathrm{~W} \mathrm{~cm}^{-2}, 0.5 \mathrm{mbar}$, respectively. Layers of various thicknesses $(50-200 \mathrm{~nm})$ were prepared by varying the deposition time. The density of the deposited material is estimated to be $2.26 \mathrm{~g} \mathrm{~cm}^{-3}$ and $1.93 \mathrm{~g} \mathrm{~cm}^{-3}$ for a-Si:H and a-Si ${ }_{0.9}\left(\mathrm{CH}_{3}\right)_{0.1}: \mathrm{H}$, respectively [5].

\subsection{Lithium insertion/de-insertion experiment}

Lithium insertion/de-insertion experiments were carried out in two-electrode half cells 
assembled in an argon-filled glove box (partial $\mathrm{O}_{2}$ pressure $<2$ ppm, partial $\mathrm{H}_{2} \mathrm{O}$ pressure $<1 \mathrm{ppm}$ ). The amorphous silicon layers were used as the working electrode and a Li-metal sheet (99.9\% purity, Aldrich) as the counter electrode. The electrolyte was $1 \mathrm{M} \mathrm{LiClO}_{4}$ (battery grade, 99.99\% purity, Aldrich) in propylene carbonate (99.7\% purity, Sigma-Aldrich).

The cell enabling optical observation of the surface evolution of the sample during lithiation/delithiation is shown in Fig. 1. A slightly different cell was used for samples deposited on c-Si. Preliminary experiments have shown that illumination of the sample during the lithiation causes a peeling off of the layer, probably due to a light-induced photo-current in the c-Si substrate. Hence, for layers deposited on c-Si, lithiation was conducted in the glove box in the dark, i.e. with a stainless steel cover instead of the glass window shown in Fig.1.

The cells were cycled galvanostatically. In most cases, lithiation of the amorphous silicon electrode was carried out from the initial open-circuit voltage down to $0.025 \mathrm{~V} \mathrm{vs}$. $\mathrm{Li} / \mathrm{Li}^{+}$, then delithiation was performed between $0.025 \mathrm{~V}$ and $2 \mathrm{~V}$. In some cases (see below) only a partial lithiation was performed. On c-Si substrates the voltage limit for lithiation was increased to $125 \mathrm{mV}$ to avoid lithiation of the crystalline silicon substrate [6].

Cells were tested at various charge/discharge current densities corresponding to charge and discharge rates in the $\mathrm{C} / 40-\mathrm{C} / 2$ range (current densities from 3 to $30 \mu \mathrm{A} \mathrm{cm}^{-2}$, depending on methyl content and film thickness). An Autolab PGSTAT12 was used for operando optical microscopy experiments. For a better resolution of potential measurements, in particular at the very early stage of lithiation, a multi-channel Bio-Logic VMP3 was also used for control experiments. The latter allows for recording much faster measurements and higher number of data. All experiments were performed at room temperature $\left(20-23^{\circ} \mathrm{C}\right)$.

\subsection{Optical Microscopy}

Optical microscopy characterizations were performed on a Nikon Optiphot 2 microscope. Two objectives of different magnification were used: $\times 20$ (numerical aperture 0.4 ) and $\times 40$ (numerical aperture 0.5). The time evolution of the Si layer during lithiation/delithiation cycles was monitored by a color camera with a field of view of $550 \times 345 \mu \mathrm{m}^{2}$ and $275 \times 173 \mu \mathrm{m}^{2}$ for $\times 20$ and $\times 40$ magnifications, respectively. Great care was taken to adjust the color settings in order to avoid over or under saturation of any of the three RGB channels of the camera during the lithiation process. The same settings were kept for all samples. Video sequences were recorded at the rate of one image per second.

\subsection{AFM Characterization}


3D structural deformations of the Si layers were characterized by Atomic Force Microscopy using a PicoSPM (Molecular Imaging) in AC mode and Si tips (HQ-NSC16, $\mu$ Masch, spring constant $\sim 45 \mathrm{~N} \mathrm{~m}^{-1}$, resonance frequency $\sim 160 \mathrm{kHz}$ ). Crystalline silicon was chosen as substrate to benefit from very flat surfaces allowing for high-resolution imaging. AFM characterizations of the lithiated surfaces were performed ex situ in air. For that purpose, a specific procedure was implemented to neutralize the Li reactivity and keep the structural deformation of the lithiated layers in a steady-state as close as possible of that before air exposure. The lithiations were performed inside the glove box. After lithiation and removal of the electrolyte and the counter electrode, the cell was hermetically closed by a glass slide inside the glove box within a few minutes and taken out in air. Then, the samples were first characterized by optical microscopy without opening the cell. Control experiments have shown that no significant evolution of the microscopy images takes place during this procedure. Afterwards the lithiated layers were exposed to air for $24 \mathrm{~h}$, then rinsed in EtOH (short rinsing followed by $5 \mathrm{~min}$ sonication). After such a posttreatment, evolution of the surface morphology was not observed anymore, the surface morphology remaining stable for long-lasting (months) time.

\section{Experimental results}

3.1 In situ monitoring of lithiation/delithiation by optical microscopy

We present here operando characterizations by optical microscopy of the first lithiation/delithiation cycles of a-Si:H and a-Si ${ }_{0.9}\left(\mathrm{CH}_{3}\right)_{0.1}: \mathrm{H}$ layers (thickness of $100 \mathrm{~nm}$ ). The potential evolution recorded during this first cycle is shown in Fig. 2a for pure a-Si:H and in Fig. 2b for a-Si ${ }_{0 .}\left(\mathrm{CH}_{3}\right)_{0.1}: \mathrm{H}$. A current density of $\sim \pm 32 \mu \mathrm{A} \mathrm{cm}^{-2}$ is applied for pure a-Si:H, and of $\sim \pm 28$ $\mu \mathrm{A} \mathrm{cm} \mathrm{cm}^{-2}$ for a-Si ${ }_{0.9}\left(\mathrm{CH}_{3}\right)_{0.1}: \mathrm{H}$, corresponding approximately to a $\mathrm{C} / 2$ rate. In both cases a characteristic lithiation potential plateau [5] is observed (at $210 \mathrm{mV}$ for a-Si:H and $180 \mathrm{mV}$ for a$\left.\mathrm{Si}_{0.9}\left(\mathrm{CH}_{3}\right)_{0.1}: \mathrm{H}\right)$. The non-null value of potential indicates a partial lithiation of the active thin films. The constant value of the potential alongside the plateau indicates a lithiation mechanism involving the progressive invasion of the silicon layer by a lithium rich phase of constant Li concentration: the potential of the plateau is correlated to the stoichiometry $z$ of the invading phase $\mathrm{Li}_{z} \mathrm{Si}$ during this process [6].

In spite of the very similar shapes of the two curves, minute differences can be observed (see Fig. 2 and Appendix B Fig. S1). In the case of pure a-Si:H, the potential gradually decreases from the open-circuit potential to the potential plateau. In the case of methylated silicon, the potential immediately drops to a value below the lithiation plateau, then rapidly increases until stabilization at the lithiation plateau. The magnitude of the initial potential drop increases upon increasing the 
current density or the layer thickness (see Appendix B, Fig. S1). The potential minimum can even be negative. This does not mean that the potential at the surface of the working electrode is negative vs $\mathrm{Li} / \mathrm{Li}^{+}$: it is due to the very high resistance of the layer, which requires the building of a possibly large negative voltage in series with the inter-electrode potential.

Similar potential behaviors are obtained whatever the nature of the electrode substrate is i.e., stainless steel or crystalline silicon (see Appendix B Fig. S2).

\subsubsection{First lithiation/delithiation of pure silicon layers}

Figures 3a-f shows images extracted from the video sequence recorded during the first lithiation-delithiation cycle for a pure a-Si:H, $100 \mathrm{~nm}$ thick sample. A continuous and almost spatially uniform color change of the sample is observed at the early stages of the lithiation (Figs. 3a-b). This color change is observable over a limited period (corresponding to $\sim$ one fifth of the duration of the first lithiation). Then the color remains almost constant until the end of the lithiation (Figs. 3c-d). Upon delithiation the color remains constant over a long period of time (Figs 3d-e) then rapidly changes just before the end of delithiation (Fig. 3f). Reversible color changes are observed during the following cycles, the color of the surface oscillating between two different colors, one corresponding to the lithiated state (color observed in Figs. 3c-d) and the other to the delithiated state (color observed in Fig. 3f). Similar color evolutions are observed during lithiation of a-Si:H layers of various thicknesses and for various $\mathrm{C}$-rates below $\mathrm{C} / 1$. The color changes are uniform on the whole sample surface.

Because $\mathrm{Li}$ insertion is known to give rise to volume expansion, it is very tempting to assign the color changes observed during lithiation to variations of the layer thickness [9]. However, modification of the optical refractive index of the layer cannot be neglected, making not straightforward the interpretation of color variation in terms of thickness variation only. This issue will be further discussed hereafter.

\subsubsection{First lithiation/de-lithiation of methylated layers}

Figures $4 \mathrm{a}-\mathrm{h}$ shows images extracted from the video sequence recorded during the first lithiation-delithiation cycle of an a-Si $i_{0.9}\left(\mathrm{CH}_{3}\right)_{0.1}: \mathrm{H}, 100-\mathrm{nm}$-thick layer. Contrary to what is observed for non-methylated layers (see Sec. 3.1.1), a non-uniform color change is noticed at the early stages of the lithiation process: the nucleation of small spots exhibiting a different color is observed. These spots expand very rapidly and isotropically with time, leading to the formation of circular disks. According to the results shown in the previous section, these color changes can confidently be attributed to localized lithiation. 
At a given time, lithiation spots of various size are observed revealing locally different advancement of lithiation process: big spots correspond to early lithiation and small spots to more recent lithiation. Thus, before the merging of the spots (Fig. 4d) the optical images - at a given time - provide a history of the lithiation progress, showing in the same picture different lithiation states. At longer time, the spots eventually merge, leading to a uniform surface coloration (Fig. $4 \mathrm{~d}$ ). This recovering of the surface homogeneity coincides with the end of the lithiation plateau. As in the case of non-methylated layers (Fig. 3), the color remains constant during most of the delithiation time (Figs 4e-f) and rapidly changes at the very end (Figs. 4g-h).

The non-uniform color change observed at the beginning of the first lithiation of methylated layers is observed for all the investigated C-rates on 100- and 200-nm-thick layers, and only for high $\mathrm{C}$-rate in the case of thinner samples $(50 \mathrm{~nm})$. Our experiments show that the spatially non uniform lithiation is systematically correlated to the observation of a potential drop at the very beginning of the potential-versus-time curves recorded during the lithiation. This point will be discussed in Sec. 4.2.

\subsection{Ex situ characterizations of partially lithiated methylated layers}

Methylated a-Si layers were partially lithiated (current density $\sim 34 \mu \mathrm{A} \mathrm{cm} \mathrm{cm}^{-2}$ ) in order to characterize by AFM the structural deformation induced at the lithiation spots. The surface state after partial lithiation was first characterized ex situ by optical microscopy before (Fig. 5a) and after air exposure and rinsing in $\mathrm{EtOH}$ (Fig. 5b, see Sec. 2.4 for details on the experimental procedure). As for methylated layers deposited onto stainless steel, the optical images reveal a non-uniform lithiation process meaning that this behavior is intrinsic to the material. Before air exposure and rinsing (Fig. 5a), the optical images of surface kept under Ar atmosphere display disk-like lithiated areas similar to those observed during in situ observations in operando conditions. No evolution of their density or shape was detected over time, indicating a stable lithiation state.

After long air exposure followed by EtOH rinsing, the images display a clean surface free of electrolyte residues (Fig. 5b). A color change is observed as compared to Fig. 5a. It is ascribed to sample drying (for recording the image of Fig. 5a, the electrolyte has been evacuated from the cell but the sample has not been dried), which affects the refractive index contrast at the layer surface. Moreover, for the lithiation spots (whose size and shape are identical before and after rinsing), a chemical change can also contribute to the color change, arising from lithium oxidation upon air exposure and EtOH rinsing. Raman spectroscopy confirms an evolution of the chemical composition of the spots upon rinsing, through a change of their local optical properties: the lithiated areas are initially opaque and then become almost transparent after air exposure and EtOH 
rinsing, allowing for detecting the substrate vibrational signature (see Appendix B, Fig. S3). Even though one cannot totally discard the fact that the chemical oxidation can induce structural change at the atomic scale, it is reasonable to assume that these structural changes remain minor with respect to the volume expansion induced by lithium insertion.

Figure 5c shows a 3D AFM image of one lithiation spot (the spot is indicated by an arrow on optical images Figs. 5a-b) and thickness profiles across different spots obtained from AFM images. The spots exhibit a cone-like shape with a radial extension at least two orders of magnitude larger than their thickness. Small lithiation spots are almost conic, whereas the bigger ones are truncated cones with a sloping edge and a flat top. Hereafter the center of the spots corresponding to the area with constant thickness will be named the core and the surrounding part with variable thickness, the sloping edge.

Detailed analysis of the spot morphology is displayed in Fig. 6. The internal diameter (core diameter) of the spots, their height and the slope of the sloping edge are plotted as a function of their external (basal) diameter and compared for layers of various thicknesses. For the same external diameter, the core diameter is smaller for thicker samples, indicating a slower expansion of the core (Fig. 6a). The height of the small spots increases with their diameter (Fig. 6b). The height of truncated cones remains almost constant when their diameter increases. As expected, the height of the spots increases with the layer thickness: in $200 \mathrm{~nm}$ thick layers it is almost doubled as compared to $100 \mathrm{~nm}$ thick layers. The slope of the sloping edge (Fig. 6c) decreases with increasing the spot external diameter.

\section{Discussion}

The main experimental results are twofold: the possibility of monitoring the lithiation progress in a-Si films by operando optical microscopy is demonstrated, and a spatially non-uniform lithiation of methylated amorphous silicon layers is evidenced and quantitatively analyzed.

\subsection{Color/thickness variations relationship}

As expected and confirmed by AFM characterizations of isolated lithiation spots, the color change upon lithiation is correlated to the layer thickness variations induced by lithium insertion. In order to perform a quantitative analysis of the structural deformation from the observed color change, characterizing the color through a single quantity rather than through the Red-Green-Blue (RGB) values recorded by the camera is highly desirable. This encoding is classically performed using the Hue-Saturation-Value (HSV) representation. On this basis, the color is coded by the hue $H$, which is an angular variable varying from $0^{\circ}$ (pure red) to $360^{\circ}$ (same color), with values of $120^{\circ}$ 
corresponding to pure green and $240^{\circ}$ corresponding to pure blue. Using the optical properties of the materials used in our study, we have calculated the hue of the a-Si layers as a function of their thickness under a blackbody illumination such that used in our optical microscopy experiments (see appendix A). In the 0-200 $\mathrm{nm}$ range, a simple linear relationship is found between a reduced hue value $h$ and the layer thickness:

$$
h=3.78-0.0146 l
$$

where $l$ is the layer thickness, expressed in $\mathrm{nm}$, and $h$ the reduced hue which changes by one unit when the hue $H$ undergoes a circular change from $0^{\circ}$ to $360^{\circ}$ and linearly scales with $H$ in between. Using Eq.1, the color experimentally measured can be translated into a thickness corresponding to a homogeneous amorphous silicon film. The result is shown in Fig. 7a for the 100 $\mathrm{nm}$ a-Si:H sample displayed in Fig. 3. From the beginning of the lithiation to $1400 \mathrm{~s}$, the calculated thickness increases from $100 \mathrm{~nm}$ (the thickness of the deposited layer) to $~ 140 \mathrm{~nm}$.

Figure $7 \mathrm{~b}$ compares our results with the thickness increase induced by lithiation reported by Wang et al. [7]. The normalized thickness calculated from the color analysis is plotted as a function of the fraction of the layer invaded by the lithium-rich phase to enable comparison with volume expansion reported in [7]. Our results match well with those reported by Wang et al. in the first stages of the lithiation as long as the fraction of the Li-rich phase invading progressively the $\mathrm{Si}$ layer remains below 0.35 , meaning that within this range the layer thickness can reasonably be determined through the color variation using Eq.1. This result might appear surprising since during the two-phase lithiation stage - as long as the Si layer is not fully invaded by the Li-rich phase lithiation is not homogeneous in depth and the calculated thickness does not a priori match that of the Si layer. In addition, Raman analysis (Appendix B, Fig. S3) as well as previous FTIR characterizations [19] indicate that the Li-rich phase is optically absorbing over a large spectral range. However, as long as a small fraction of the layer is lithiated, the optical properties of the layer should remain close to those of the non lithiated Si part: even if the lithiated phase becomes absorbing, the light absorption upon crossing the layer remains low enough for allowing interferences to take place, and the average refractive index experienced by the light crossing the layer remains close to that of unlithiated $\mathrm{Si}$.

At higher lithiation level (fraction of Li-rich phase > 0.35) the Li-rich phase becomes dominant and the optical properties eventually change. Such is obviously the case during most of the cycle when a constant thickness is calculated (plateau at $\sim 150 \mathrm{~nm}$ in Fig. 7a), in agreement with the absence of change in the measured color. The calculation of the thickness from Eq. 1 is then nonrelevant.

The color change observed at the end of the delithiation is also certainly due to a thickness 
decrease of the layer. However, the material has been deeply transformed by lithiation and delithiation, and its optical properties probably differ from those of the original material. A direct determination of the layer thickness is not possible, only a determination of the optical path, i.e., the product of thickness by the optical refractive index.

\subsection{Non-uniform lithiation}

The non-uniform color change described in Sec. 3.1.2 can undoubtedly be attributed to a spatially non-uniform lithiation mechanism. Whereas in pure a-Si:H the first lithiation proceeds via the invasion of a Li-rich phase $\mathrm{Li}_{\mathrm{z}} \mathrm{Si}[7,8]$ whose thickness increases uniformly and linearly with time, the mechanism is more complex for a-Si $i_{1-\mathrm{x}}\left(\mathrm{CH}_{3}\right)_{\mathrm{x}}: \mathrm{H}$ layers. Our recent results [6] show that the first lithiation also occurs via a two-phase mechanism with a composition of the Li-rich phase that depends on the methyl content. In particular, for $x=0.1$, the Li content is found to be $~ 1.5$ [6]. One can therefore assume here that the Li-rich phase first invades the methylated layer in a limited number of lithiation spots, and then expands from these spots.

As indicated above, non-uniform lithiation is systematically associated with the occurrence of a voltage drop at the very beginning of the lithiation. This voltage drop is likely due to the electrical resistance of the layer and to the lithiation current. In particular, it is known that methylated silicon is much more resistive than a-Si:H. From optical gap measurements [17], one can expect an increase by two orders of magnitude in the resistivity for $x=0.1$ methylated silicon as compared to a-Si:H.

Non-uniform lithiation of battery electrodes has already been reported for composite (inhomogeneous) electrodes $[20,21]$. In these cases, the non-homogeneous lithiation is a direct consequence of the inhomogeneous structure/composition of the electrode, the most accessible active grains being the first to be lithiated. In the present case, the methylated amorphous silicon thin films are supposed to be homogeneous in composition. However, the experimental correlation between non-uniform lithiation and the existence of a large voltage drop at the beginning of the lithiation leads us to postulate that electrically the layers are not strictly homogeneous. Plausibly, lithiation preferentially starts at some locations (defects whose structural or electronic nature remains to be clarified) exhibiting a lower electrical resistance than their surroundings. The current density at these defects is expected to be much larger than the average current density, thus favoring a very rapid local invasion of the whole layer thickness by the Li-rich phase (Fig. 8a). Since the first lithiation takes place according to a two-phase mechanism, lithiation can only occur at the sharp phase boundary between non lithiated silicon and the lithium-rich phase $\mathrm{Li}_{\mathrm{z}} \mathrm{Si}$ [7]. Hence the 
appearance of lithiation spots induces the formation of new lithiation sites at their interface with non lithiated silicon, inducing the radial expansion of the spots, which is consistent with the experimental observations. It is noteworthy that $2 \mathrm{D}$ expansion of the spots is isotropic, meaning that the composition of the methylated layer is mostly homogeneous, disregarding the existence of point defects at which the lithiation starts.

From the shape of the lithiation spots given by AFM one can infer that the core of larger lithiation spots corresponds to regions where the lithium rich phase has invaded in depth the silicon layer. Conversely, at the boundary of these spots, the lithium-rich phase and unlithiated silicon coexist throughout the layer, the lithium rich phase thickness decreasing with increasing the distance to the center of the spot (Figs. 8b-c).

During the expansion of the first lithiation spots, other channels, corresponding to location somewhat less conducting than the defects associated to the first lithiation spots, can also capture a (small) fraction of the current and start to be lithiated. When the whole layer thickness has been lithiated at these locations, new lithiation spots appear and start to expand radially.

In the scheme described in Fig. 8, we suppose that the expansion is more favorable at the interface between the silicon layer and the electrolyte. Presently, there is no experimental support for this assumption. Different expansion schemes could be proposed, including expansion more favorable at the interface with the substrate. In any case, the lithiation spots are flat mesas with sloping edges getting thinner from the center to the outside. As long as a spot does not merge with another one, this shape is preserved and radially expands. This implies that lithium and electrons can both reach all the sites at the boundary between the lithiated and the unlithiated material. This is possible through the lithium-rich phase $\mathrm{Li}_{\mathrm{z}} \mathrm{Si}$ (arrows in Fig. 8c) because the lithium-rich phase is a fair electron and $\mathrm{Li}^{+}$conductor [1], much better than unlithiated silicon.

As mentioned above, the suggested mechanism assumes that during the non-uniform lithiation process, the reaction $\mathrm{Li}^{+}+\mathrm{e}^{-} \rightarrow \mathrm{Li}$ can only occur at the boundary of lithiation spots (the zone marked as red spots in Fig. 8). In this case the whole current flows through a limited "active" region at the boundary of the lithiated spots. If we neglect the variation in the radial expansion of the spot sloping edges, the area of this active zone should be proportional to the length of the spot boundaries. Conversely, the electrode electrical resistance should be inversely proportional to this length. This length can be determined from the images extracted from the video sequences recorded during the first lithiation. Obviously it is very small at the very beginning of the lithiation, because the spots are very few and very tiny (Fig. 9a). It is again very small when all lithiated zones merge at the end of the lithiation plateau (Fig. 9c). In Fig. 9, the inverse of the perimeter of the lithiated zones is compared to a voltage drop calculated considering a fixed value for the lithiation plateau 
$(0.2 \mathrm{~V})$. The two quantities are in good agreement, consistently with our model. In view of the various approximations performed for obtaining the graphs in Fig. 9 (especially for the estimation of the ohmic drop), we do not push further the quantitative analysis of this correlation.

\section{Conclusion}

Operando color microscopy and ex situ AFM were used to monitor lithiation of pure (a$\mathrm{Si}: \mathrm{H})$ and methylated $\left(\mathrm{a}-\mathrm{Si}_{1-\mathrm{x}}\left(\mathrm{CH}_{3}\right)_{\mathrm{x}}: \mathrm{H}\right)$ amorphous silicon thin layers. During the first lithiation, our observations reveal a non-uniform lithitiation of $\mathrm{a}-\mathrm{Si}_{1-\mathrm{x}}\left(\mathrm{CH}_{3}\right)_{\mathrm{x}}: \mathrm{H}$ layers, related to the high resistance of the layers: lithiation starts at a limited number of positions then expands radially, forming circular spots. On the contrary, lithiation of pure a-Si:H is uniform, at least at the opticalmicroscopy scale. The non-uniformity of the first lithiation appears related to the resistivity of a-Si $i_{1}$ ${ }_{x}\left(\mathrm{CH}_{3}\right)_{\mathrm{x}}: \mathrm{H}$, much higher than that of pure a-Si:H.

Operando optical microscopy allows for monitoring the early thickness increase of the silicon layer induced by lithiation, and the size increase of lithiation spots. The shape of these spots and their evolution is precisely measured by ex situ AFM, using layers grown on flat crystalline silicon substrates and after setting-up a dedicated procedure minimizing damaging of lithiatiated silicon by air exposure. Raman and optical observations indicate a possible chemical change but no change in the shape and structure of the lithiation spots induced by this procedure.

Uniform and non-uniform lithiation are two extreme cases, depending on the resistivity of the material, on the current density and on the presence of (electrical) defects in the layer. A more complete study of these dependencies is currently underway. The induction of inhomogeneity by the resistive character of an invaded phase is not a singular phenomenon; it is parented to the very general mechanism of Laplacian instability, responsible for the growth of many irregular structures in various systems. From a practical viewpoint, the existence of this non-uniformity during the first lithiation of the material might appear as a serious drawback for the use of methylated amorphous silicon as an electrode material in Li-ion batteries, in view of the importance of the first lithiation cycle in the stability of the electrodes. Such is not the case since, as a matter of fact, the uniform character of the electrode is recovered before the end of the first lithiation, at the end of the lithiation plateau. Moreover, specific strategies could be thought of for circumventing the phenomenon, either by specific "electrode forming" procedures at very low current or, more conveniently, by pre-doping the material to make it more conductive.

\section{Acknowledgements}


Délégation Générale de l'Armement (DGA) is gratefully acknowledged for financial support. This work has also been supported by a public grant overseen by the French National Research Agency (ANR) as part of the "Investissements d'Avenir" program (Labex charmmmat, ANR-11-LABX0039-grant). It was partially conducted in the frame of the TREND-X research program of Ecole Polytechnique, supported by Fondation de l'Ecole Polytechnique. 


\section{Appendix A:}

The color dependence of Si thin film deposited on a metallic reflector as a function of their thickness was already studied by Mirshafieyan and Guo [9]. In order to determine this dependence in our experimental conditions, we considered the case of an a-Si:H layer deposited on an iron substrate. The iron substrate is thick enough that it totally blocks light transmission.

When the natural light source hits on the sample, two beams of light $r_{12}$ and $r_{23}$ are reflected from the two interfaces: air/a-Si:H and a-Si:H/Fe. The complex optical wave reflection coefficient $r$ can be calculated as shown in equation:

$$
r=\frac{r_{12}+r_{23} e^{-2 j \phi}}{1+r_{12} r_{23} e^{-2 j \phi}}
$$

The phase delay $\varphi$ of the optical wave crossing the silicon film of thickness $d$ is given by:

$$
\phi=\frac{2 \pi d}{\lambda}\left(n_{2}-\mathrm{jk} \mathrm{k}_{2}\right) \cos \theta_{2}
$$

where $\lambda, n_{2}-j k_{2}$ and $\theta_{2}$ are the wavelength of incident light, the complex index of refraction of a-Si:H and the propagation angle with respect to the normal of the film. The optical reflectance for the single silicon layer is given by equation:

$$
R(\lambda)=|r|^{2}
$$

The values of the real and imaginary part of the refractive index of a-Si:H and Fe were taken from the literature $[22,23]$.

Then the reflected spectrum was first converted to CIE (Commission Internationale de l'Eclairage) XYZ color coordinates [24] by assuming a natural daylight illuminant D50, then to RGB (Red, Green, Blue) coordinates with the help of RGB color space by MATLAB. The RGB coordinates are then straightforwardly transformed in HSV coordinates [25].

Figs. A1a-c shows a comparison of the calculated result with pictures obtained for a $100 \mathrm{~nm}$ and a $200 \mathrm{~nm}$ thick samples, evidencing a good agreement between our calculation and experimental colors.

Finally, the calculated dependence of the hue $h=H / 360$ as a function of layer thickness is shown in Fig. A1d. Each variation of a unit corresponds to a complete turn on the Hue color wheel. An almost linear variation of $\mathrm{h}$ as a function of thickness is found, which can be fitted by Eq. 1 . 


\section{References:}

[1] F. Ozanam, M. Rosso, Silicon as anode material for Li-ion batteries, Mater. Sci. Eng. B 213 ( 2016) 2-11.

[2] X. Su, Q. Wu, J. Li, X. Xiao, A. Lott, W. Lu, B. W. Sheldon, J. Wu, Silicon-Based Nanomaterials for Lithium-Ion Batteries: A Review, Adv. Energy Matter. 4 (2014) 1300882.

[3] M. Ashuri, Q. He, L. L. Shaw, Silicon as a potential anode material for Li-ion batteries: where size, geometry and structure matter, Nanoscale 8 (2016) 74-103.

[4] X. Zuo, J. Zhu, P. Müller-Buschbaum, Y.-J. Cheng, Silicon based lithium-ion battery anodes: A chronicle perspective review, Nano Energy 31 (2017) 113-143.

[5] L. Touahir, A. Cheriet, D. A. Dalla Corte, J.-N. Chazalviel, C. Henry-de-Villeneuve, F. Ozanam, I. Solomon, A. Keffous, N. Gabouze, M. Rosso, Methylated silicon: a longer cycle-life material for Li-ion batteries, J. Power Sources 240 (2013) 551-557.

[6] B. M. Koo, D. A. Dalla Corte, J.-N. Chazalviel, F. Maroun, M. Rosso and F. Ozanam, Lithiation mechanism of methylated amorphous silicon unveiled by operando ATR-FTIR spectroscopy, Adv. Energy Mater. 8 (2018) 1702568.

[7] J. W. Wang, Y. He, F. Fan, X. H. Liu, S. Xia, Y. Liu, C. T. Harris, H. Li, J. Y. Huang, S. X. Mao, T. Zhu, Two-Phase Electrochemical Lithiation in Amorphous Silicon, Nano Lett. 13 (2013) $709-715$.

[8] M. T. McDowell, S.-W. Lee, J. T. Harris, B. A. Korgel, C. Wang, W. D. Nix, Y. Cui, In Situ TEM of Two-Phase Lithiation of Amorphous Silicon Nanospheres, Nano Lett 13 (2013) 758-764.

[9] S. S. Mirshafieyan, J. Guo, Silicon Colors: Spectral Selective Perfect Light Absorption in Single Layer Silicon Films on Aluminum Surface and Its Thermal Tunability, Opt Express, 22 (2014) 31545-31554.

[10] L. Y. Beaulieu, K. W. Eberman, R.L. Turner, L. J. Krause, J. R. Dahn, Colossal reversible volume changes in lithium alloys, Electrochem. Solid State Lett. 4 (2001) A137-A140.

[11] R. Kumar R. Kumar, T. Y. Ohulchanskyy, I. Roy, S. K. Gupta, C. Borek, M. E. Thompson, P. N. Prasad, Strain-Induced Lithium Losses in the Solid Electrolyte Interphase on Silicon Electrodes, ACS Appl. Mater. Interf. 9 (2017) 28406-28417.

[12] C. R. Becker, K. E. Strawhecker, Q. P. McAllister, C. A. Lundgren, In Situ Atomic Force Microscopy of Lithiation and Delithiation of Silicon Nanostructures for Lithium Ion Batteries, ACS Nano 7 (2013) 9173-9182. 
A. Tokranov, B. W. Sheldon, C. Li, S. Minne. X. Xiao, In Situ Atomic Force Microscopy Study of Initial Solid Electrolyte Interphase Formation on Silicon Electrodes for Li-Ion Batteries, ACS Appl. Mater. Interf. 6 (2014) 6672-6686.

[14] X.-R.Liu, X. Deng, R.-R. Liu, H.-J. Yan, Y.-G. Guo, D. Wang, L.-J. Wan, Single Nanowire Electrode Electrochemistry of Silicon Anode by in Situ Atomic Force Microscopy: Solid Electrolyte lnterphase Growth and Mechanical Properties, ACS Appl. Mater. Interf. 6 (2014) 20317-20323.

[15] I. Yoon, D. P. Abraham, B. L. Lucht, A. F. Bower, P. R. Guduru, In Situ Measurement of Solid Electrolyte Interphase Evolution on Silicon Anodes Using Atomic Force Microscopy, Adv. Energy Mater. 6 (2016) 1600099.

[16] B. Breitung, P. Baumann, H. Sommer, J. Janek, T. Brezesinski, In situ and operando atomic force microscopy of high-capacity nano-silicon based electrodes for lithium-ion batteries, Nanoscale 8 (2016) 14048-14056.

[17] I. Solomon, M. P. Schmidt, H. Tran-Quoc, Selective low-power plasma decomposition of silane-methane mixtures for the preparation of methylated amorphous silicon, Phys. Rev. B 38 (1988) 9895-9901.

[18] I. Solomon, M. P. Schmidt, C. Sénémaud, M. D. Khodja, Band structure of carbonated silicon studied by optical, photoelectron, and X-Ray spectroscopy, Phys. Rev. B 38 (1988) 1326313270.

[19] D. A. Dalla Corte, G. Caillon, C. Jordy, J.-N. Chazalviel, M. Rosso, F. Ozanam, Spectroscopic insight into Li-ion batteries during operation: an alternative infrared approach, Adv. Energy Mater. 6 (2016) 1501768.

[20] C. Delmas, M. Maccario, L. Croguennec, F. Le Cras, F. Weill, Lithium deintercalation in $\mathrm{LiFePO}_{4}$ nanoparticles via a domino-cascade model, Nature Mater. 7 (2008) 665-671.

[21] A. Bonnefont, E. R. Savinova, K. Krischer, Stochastic and cooperative processes in far from equilibrium mesoscopic electrochemical systems, Curr. Opinion Electrochem. 4 (2017) 145151.

[22] P. B. Johnson, R. W. Christy, Optical constants of transition metals: Ti, V, Cr, Mn, Fe, Co, Ni, and Pd, Phys. Rev. B 9 (1974) 5056-5070.

[23] D. T. Pierce and W. E. Spicer, Electronic structure of amorphous Si from photoemission and optical studies, Phys. Rev. B 5 (1972) 3017-3029.

[24] J. Henrie, S. Kellis, S. M. Schultz, A. Hawkins, Electronic color charts for dielectric films 
on silicon, Opt. Express 12 (2004) 1464-1469.

[25] A. R. Smith, Color gamut transformation pairs, ACM SIGGRAPH Computer Graphics 12 (1978) 12-19. 


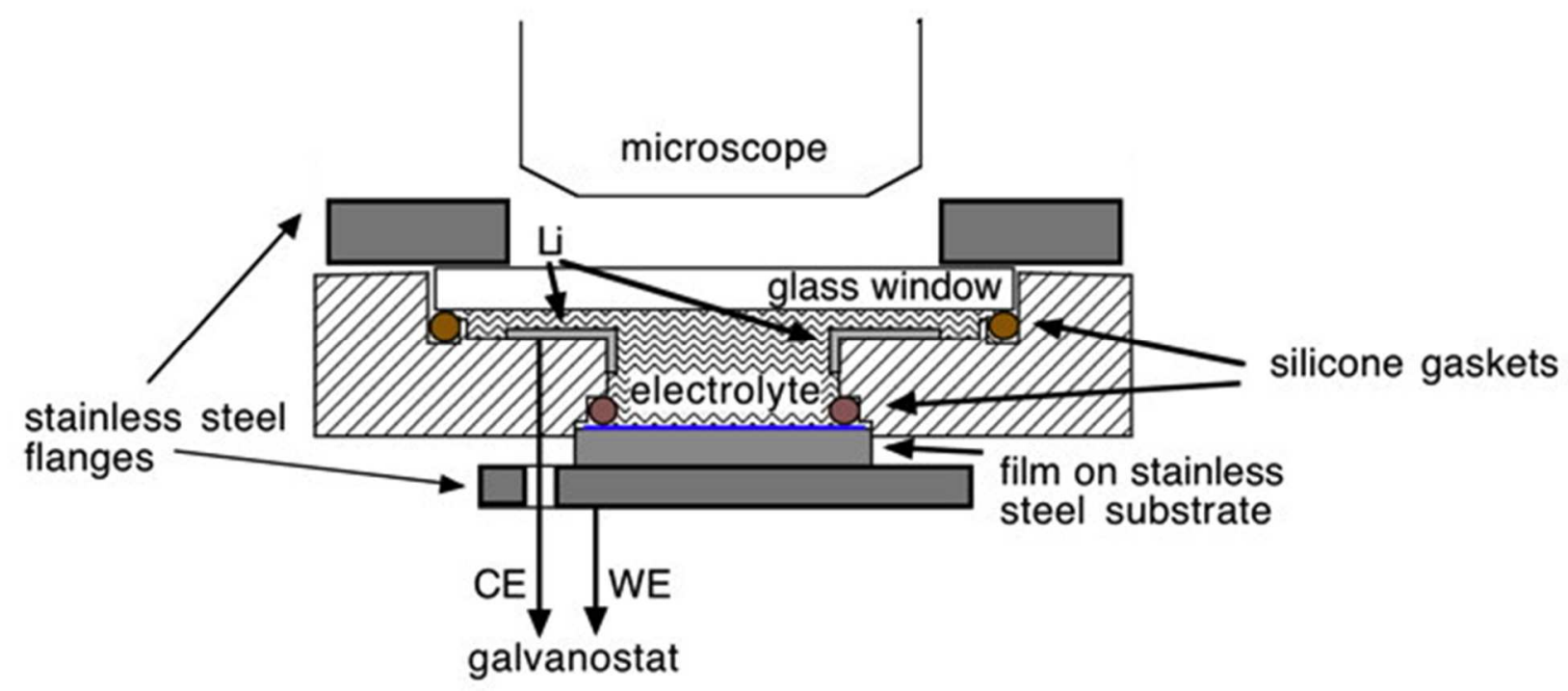

Fig. 1. Scheme of the electrochemical cell used for in situ optical microscopy. The amorphous Silicon layer atop of stainless steel substrate is represented in blue. The distance between the working electrode (WE) surface and the bottom of the glass window is $\sim 5 \mathrm{~mm}$. The Oring inner diameter delimiting the electrochemically active surface is $10 \mathrm{~mm}$. 

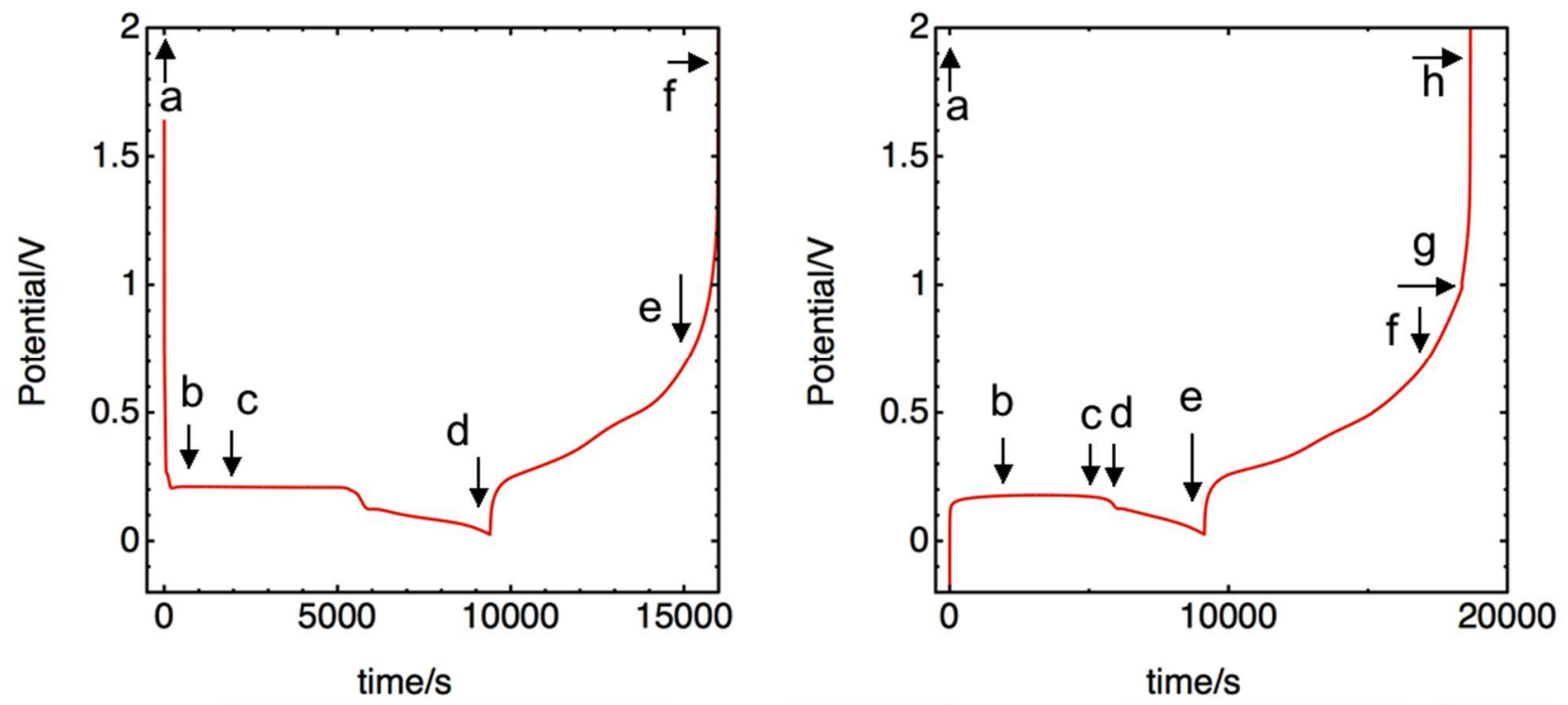

Fig. 2. Potential evolution during the first lithiation/delithiation cycle of a-Si:H (a), and a$\mathrm{Si}_{0.9}\left(\mathrm{CH}_{3}\right)_{0.1}: \mathrm{H}$ (b) 100-nm-thick films. The current density was $\sim 32 \mu \mathrm{A} \mathrm{cm}^{-2}$ and $\sim \pm 28 \mu \mathrm{A} \mathrm{cm}^{-2}$ respectively, corresponding to a $\mathrm{C} / 2$ rate. The letters point the different times at which the corresponding in-situ images in Fig.3 or Fig.4 have been recorded. The measurements were recorded with an Autolab PGSTAT12 equipment coupled with the optical microscope. Due to technical limitations the measurements of the potential at the very beginning of lithiation are missing. The usual values of open circuit potential before lithiation are in the range $2.4-2.8 \mathrm{~V}$ vs $\mathrm{Li} / \mathrm{Li}^{+}$. More accurate measurements of the very early variation of the potential evolution recorded with a VMP3 potentiostat are shown in Appendix B, Fig. S1. 


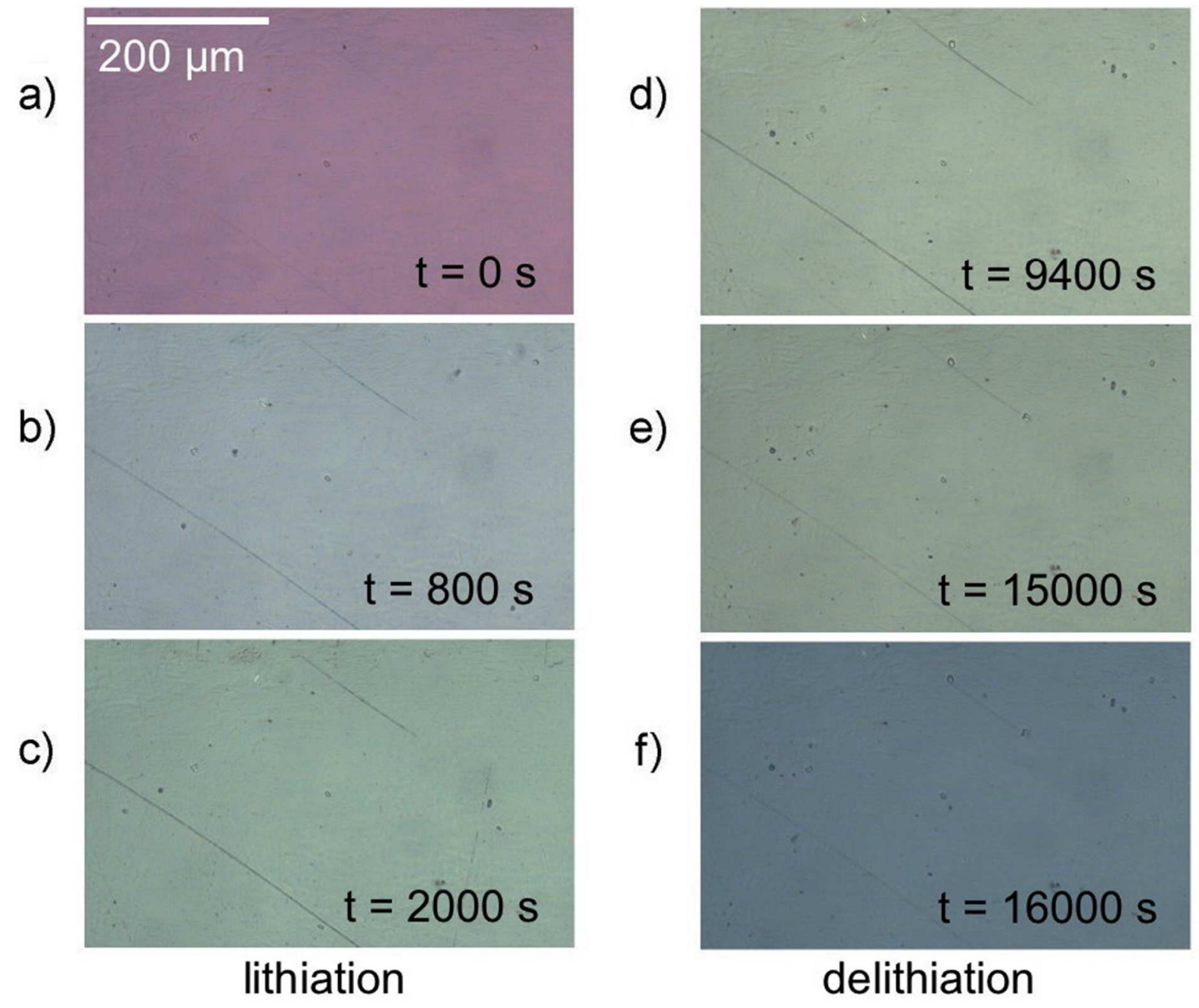

Fig. 3. In situ optical images captured during the first lithiation/delithiation of an a-Si:H, 100-nm-thick layer. (a-f) The images are recorded at different times indicated at the bottom right of each image. Images (d) and (f) correspond to fully lithiated and delithiated states respectively. 


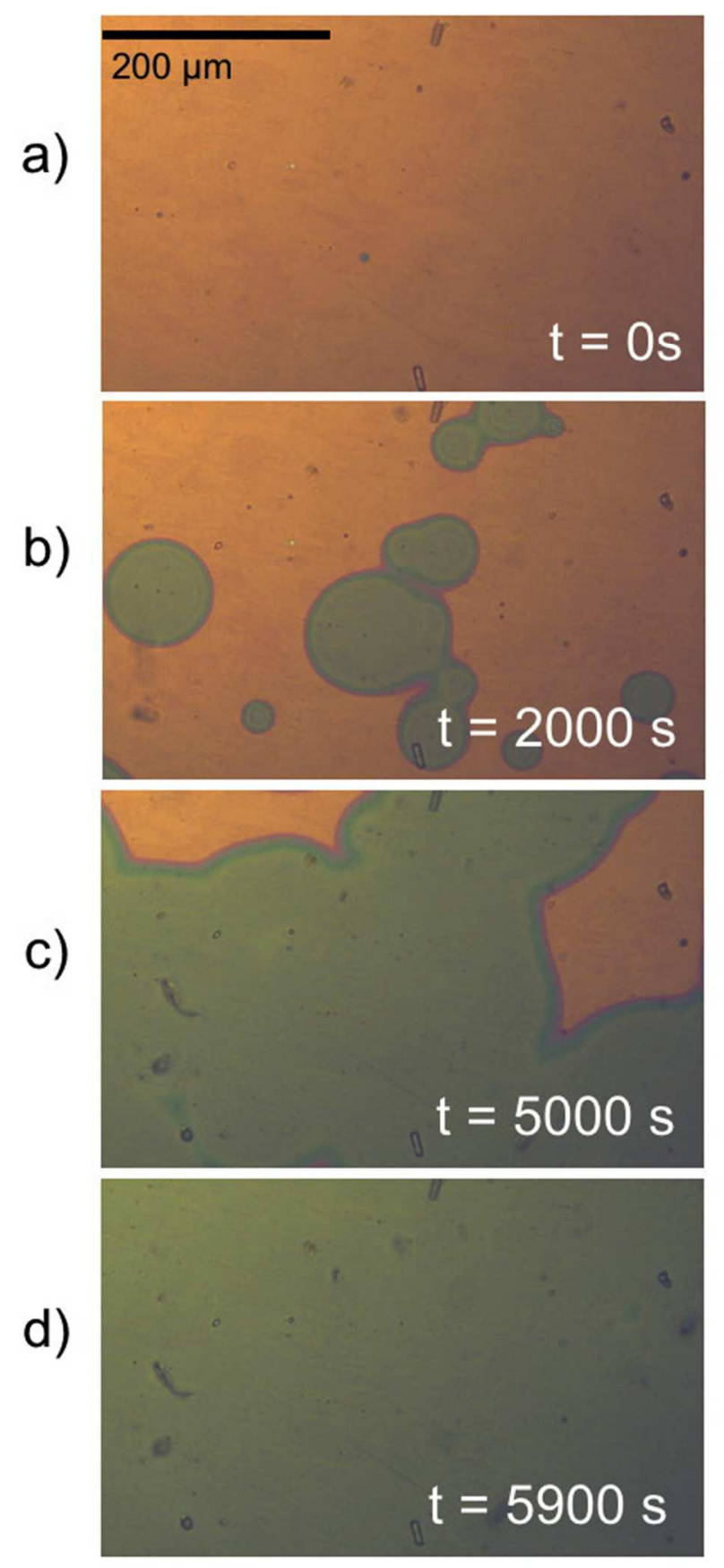

lithiation e)

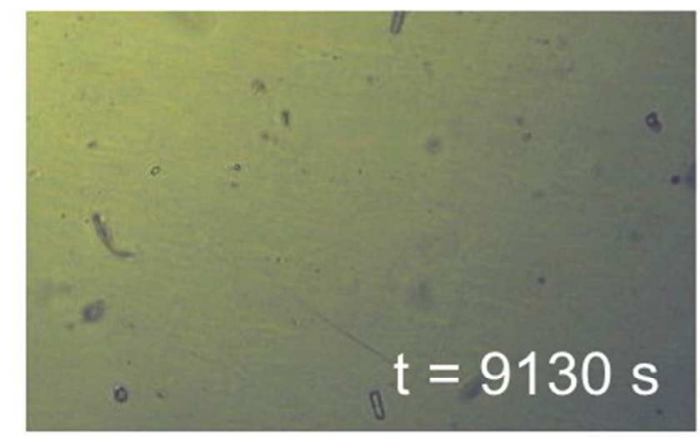

f)

$$
t=17000 s
$$

g)

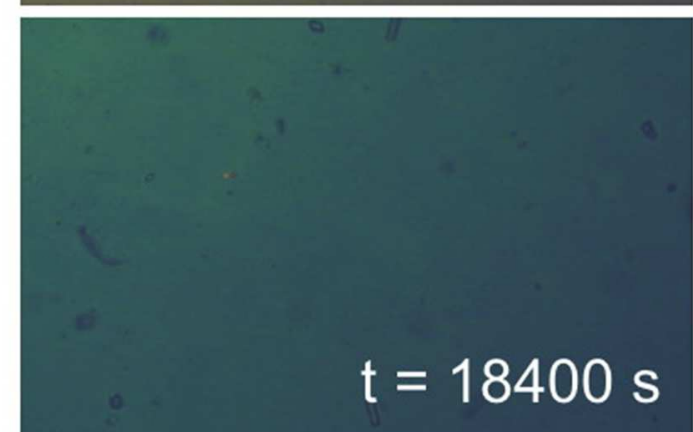

h)

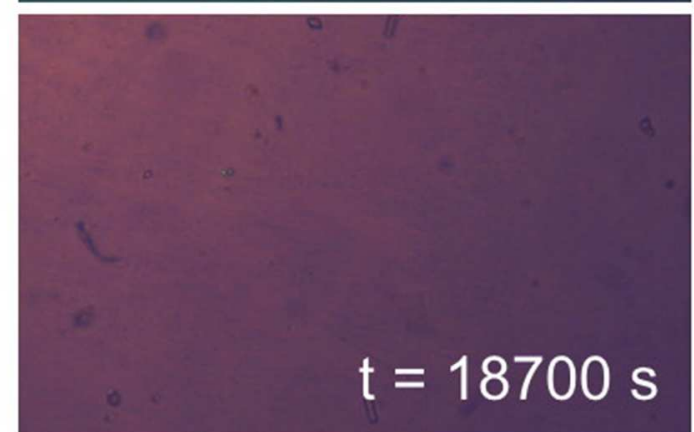

\section{delithiation}

Fig. 4. In situ optical images captured during the first lithiation/delithiation of a 100-nmthick methylated amorphous a-Si ${ }_{0.9}\left(\mathrm{CH}_{3}\right)_{0.1}: \mathrm{H}$ layer. (a-h) Images recorded at different times indicated at the bottom right of each image. Images (e) and (h) correspond to fully lithiated and delithiated states respectively. 

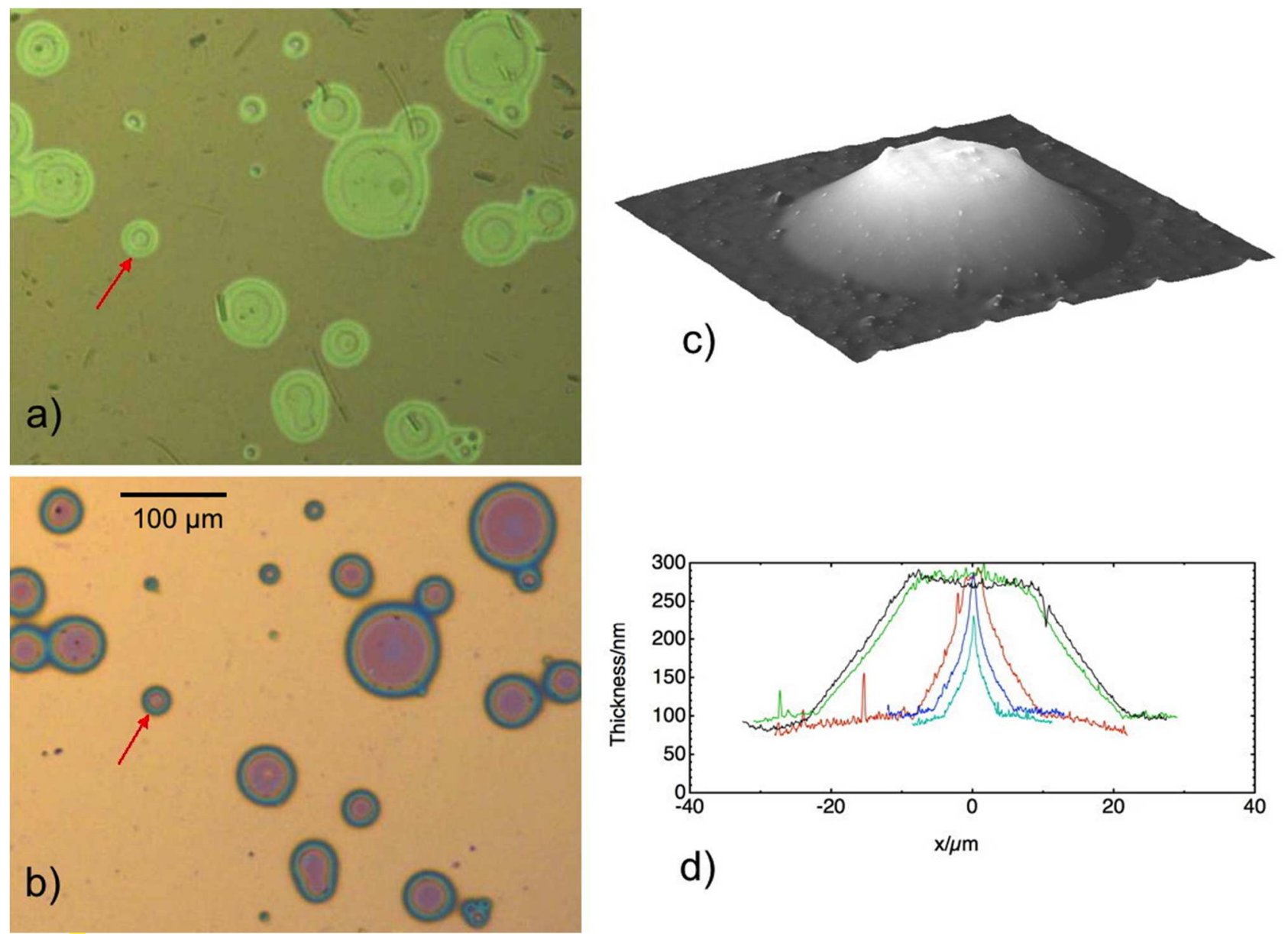

Fig. 5. (a, b) Optical images of a partially lithiated 100-nm-thick methylated a- $\mathrm{Si}_{0 . .9}\left(\mathrm{CH}_{3}\right)_{0.1}: \mathrm{H}$ layer (a) before and (b) after air exposure and $\mathrm{EtOH}$ rinsing. (c) 3D view (AFM image) of the lithiation spot pointed by the red arrow in images a) and b). (d) AFM cross-sections of lithiation spots of different sizes. 

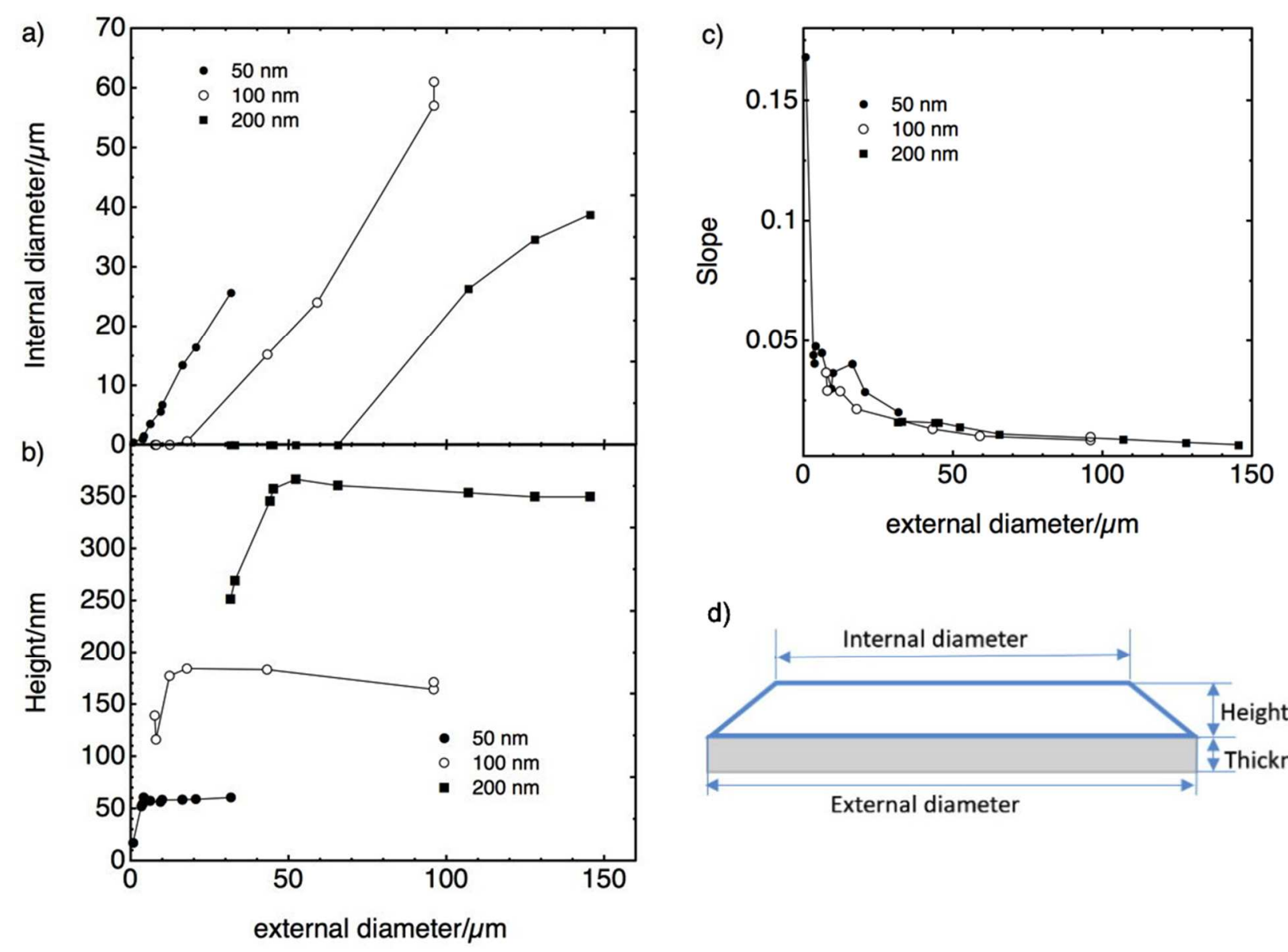

d)

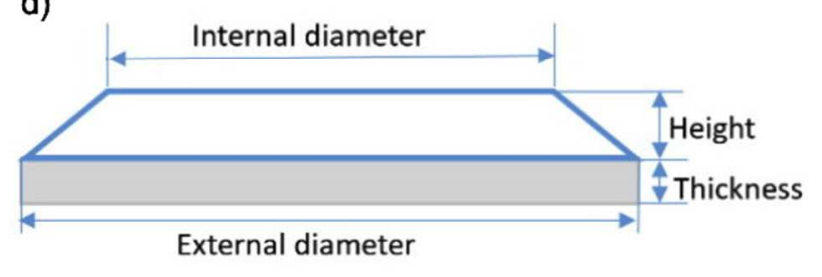

Fig. 6. Analysis of the lithiation spot geometry for a-Si $0.9\left(\mathrm{CH}_{3}\right)_{0.1}: \mathrm{H}, 50-\mathrm{nm}, 100-\mathrm{nm}$ and 200nmthick layers. (a) Core diameter (internal diameter), (b) height, and (c) slope of the sloping edge of some lithiation spots, as a function of their external diameter. (d) Schematic description of a lithiation spot. 

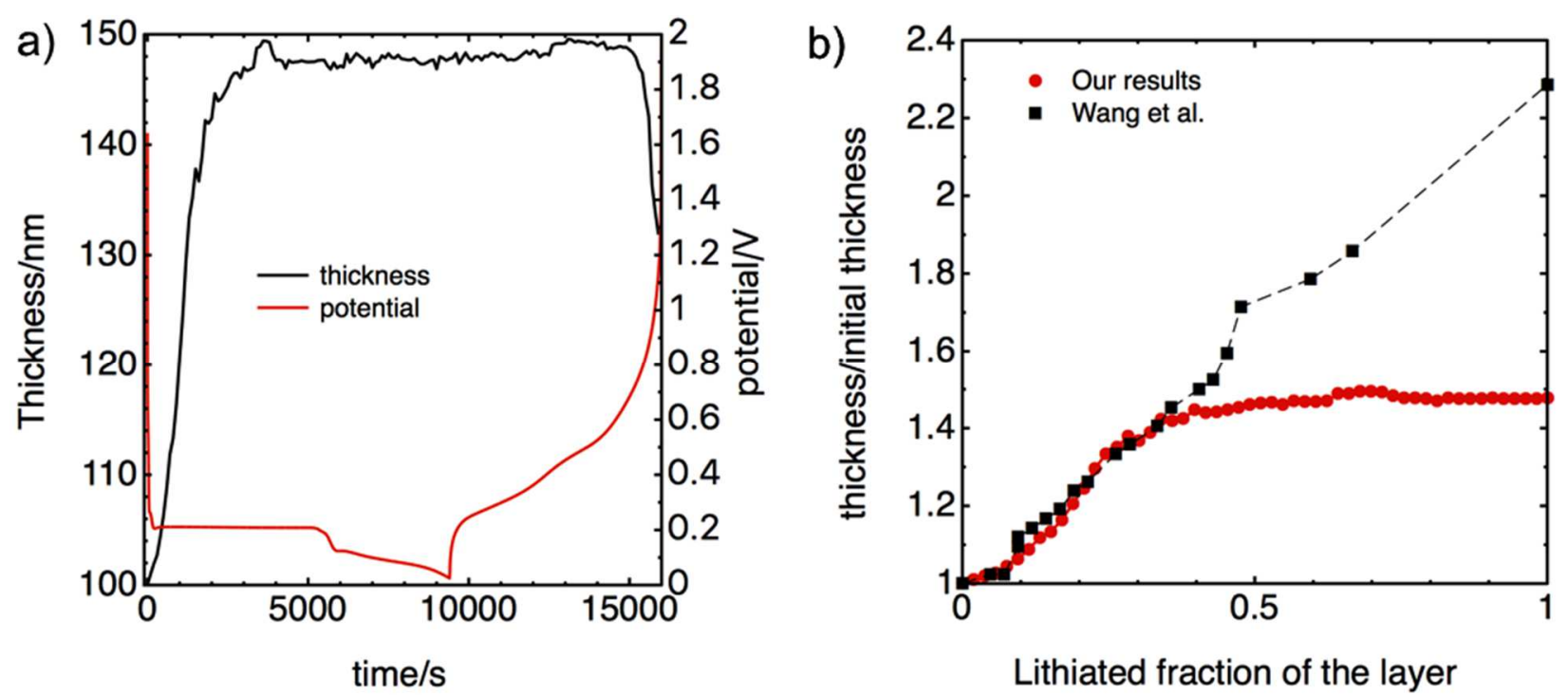

Fig. 7. (a) Calculated thickness determined from Eq.1 (black curve) of an a-Si:H layer of initial thickness $100 \mathrm{~nm}$ during the first lithiation/delithiation cycle and corresponding variation of the electrode potential (red curve) as a function of time. (b) Comparison of the normalized thickness variation shown in a) and that determined from Figs. 2g-h in ref. [7]. 

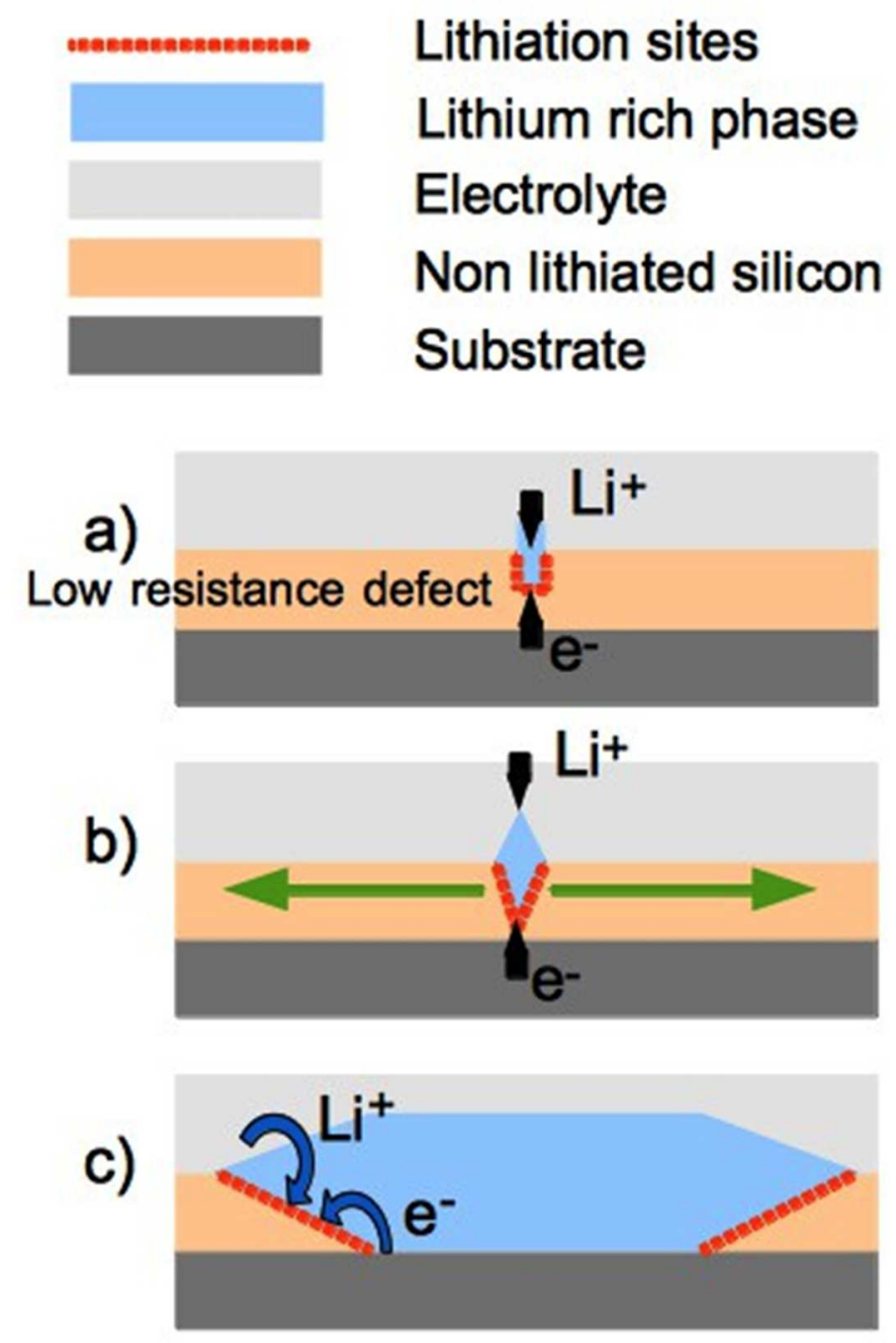

Fig. 8. Schematic description of the proposed mechanism for the non-uniform lithiation of methylated amorphous silicon. (a) lithiation starts at a low-resistance defect; (b) the lithium rich phase goes through the Si layer, the lithiation spot starts expanding radially; (c) the center of the lithiation spot is fully invaded by the lithium rich phase. As long as the two phases (lithiated and unlithiated) co-exist, the Li concentration of the Li-rich phase is constant and Li ions and electrons can only recombine at the lithiation sites located at the phase boundary between non lithiated silicon and the lithium-rich phase [7]. 
a)

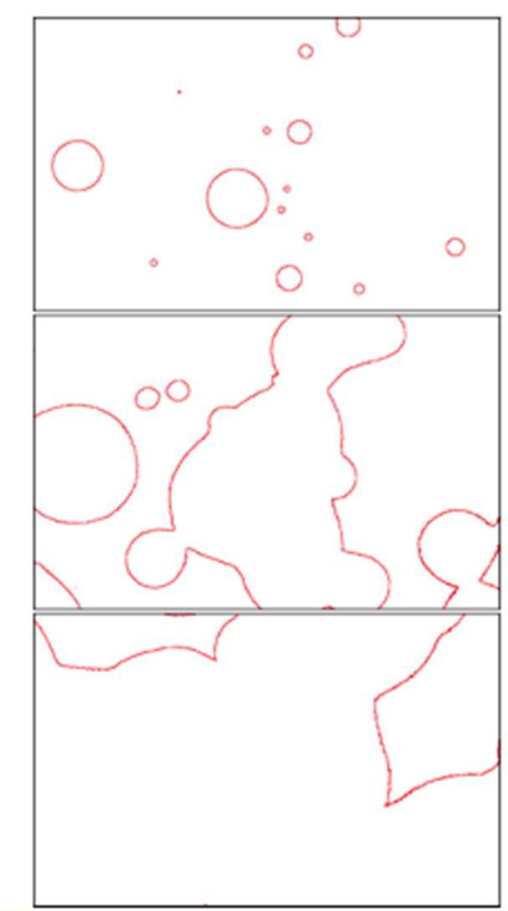

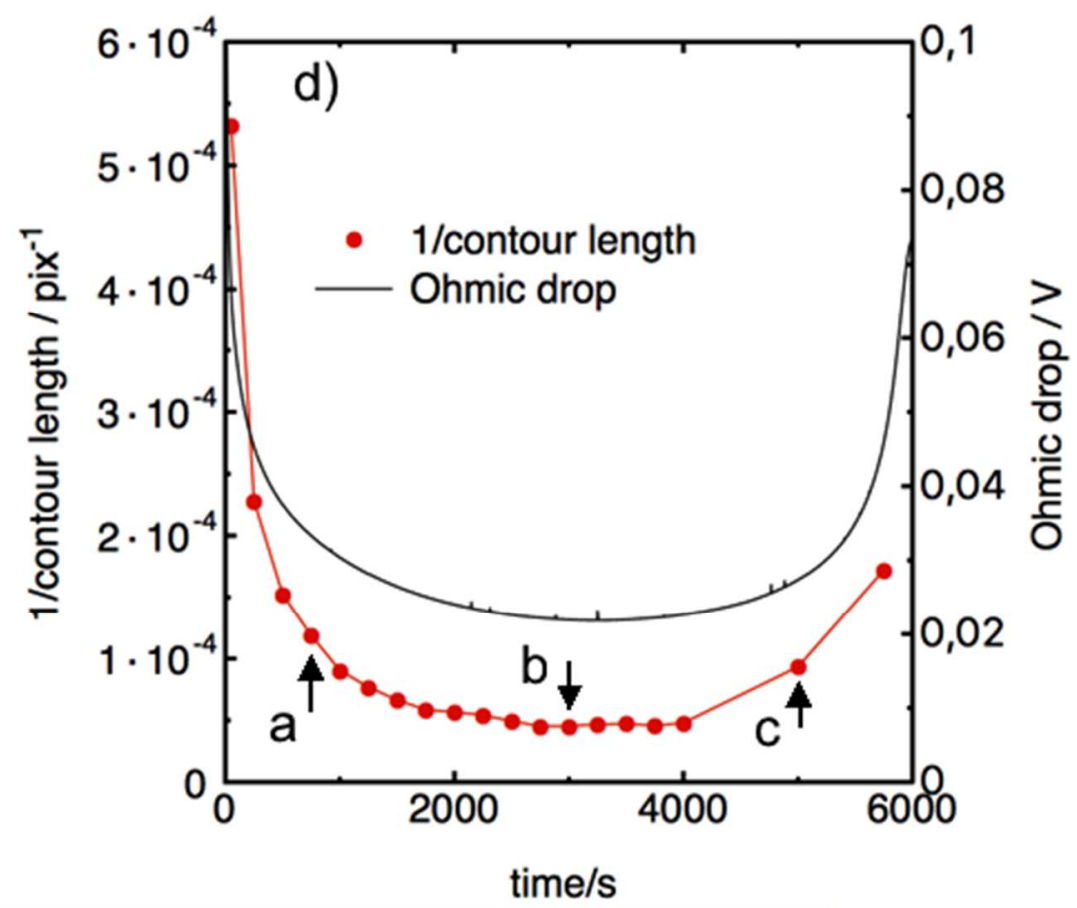

Fig. 9. a-c contours extracted from the video sequence at $750 \mathrm{~s}, 3000 \mathrm{~s}$ and $5000 \mathrm{~s}$, d) inverse of the contour length of the lithiated areas (red symbols) and ohmic drop (black curve) calculated as the difference between the potential plateau $(\sim 0.2 \mathrm{~V})$ and the potential, as a function of lithiation time (same experiment as in Fig. 2b and Figs. 4). The letters show the times corresponding to figures 9ac. 


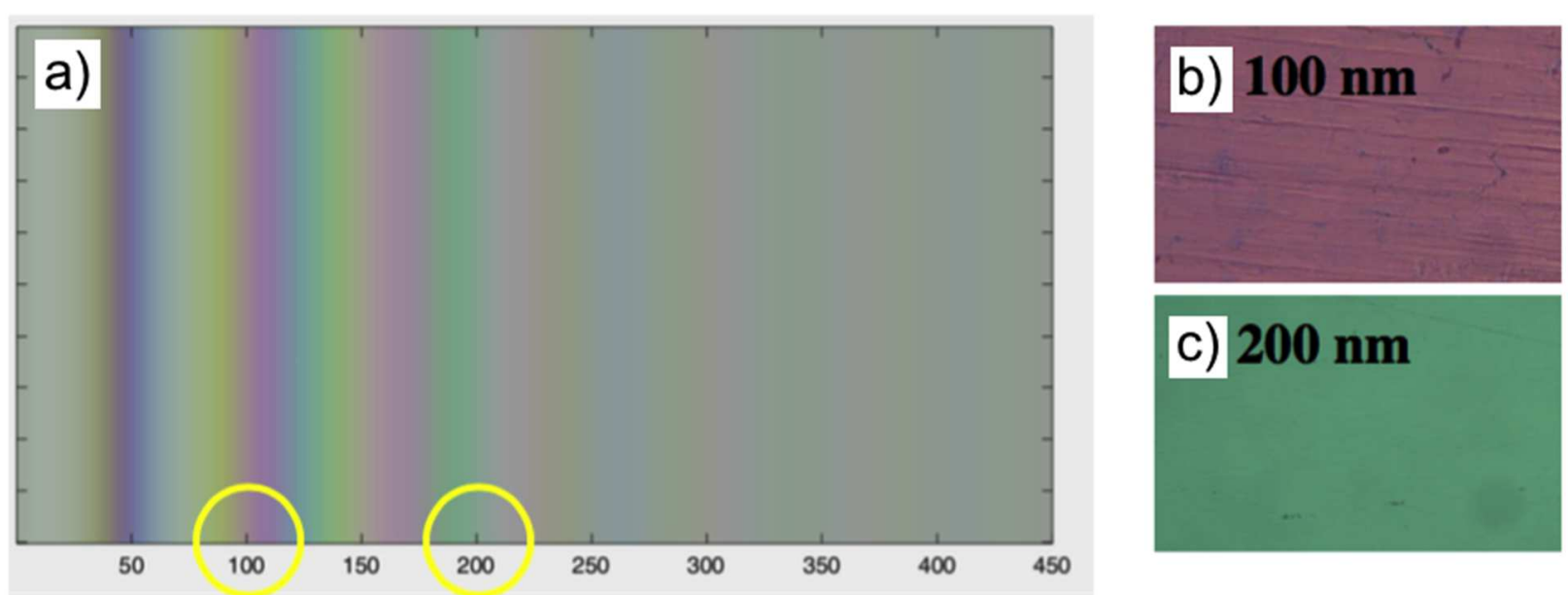

Thickness/nm

d)

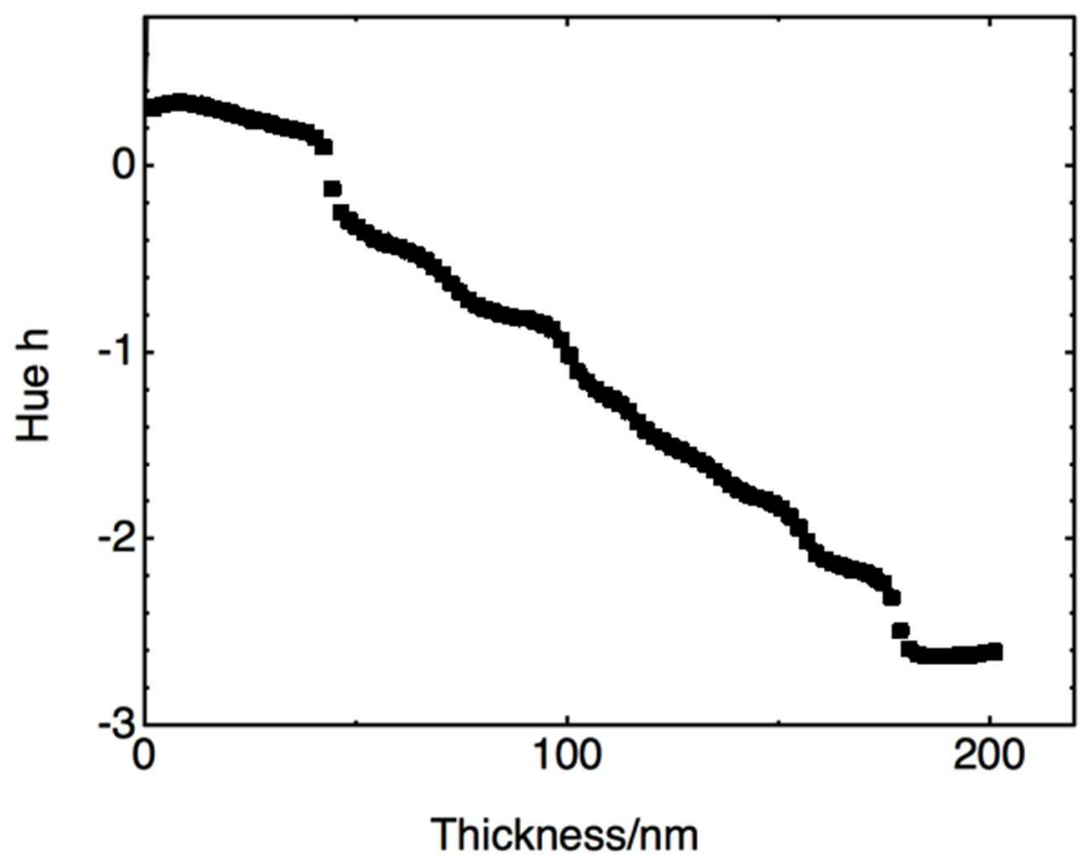

Fig. A1. (a) The calculated color of an air/a-Si:H/Fe sample as a function of thickness of the a-Si:H layer. (b) and (c) colors observed by optical microscopy for 100-nm- and 200-nm- thick a-Si:H thin layers on a stainless steel substrate. (d) Dependence of the calculated hue $h$ as a function of the a-Si:H layer thickness. 
Appendix B.

Supplementary data.
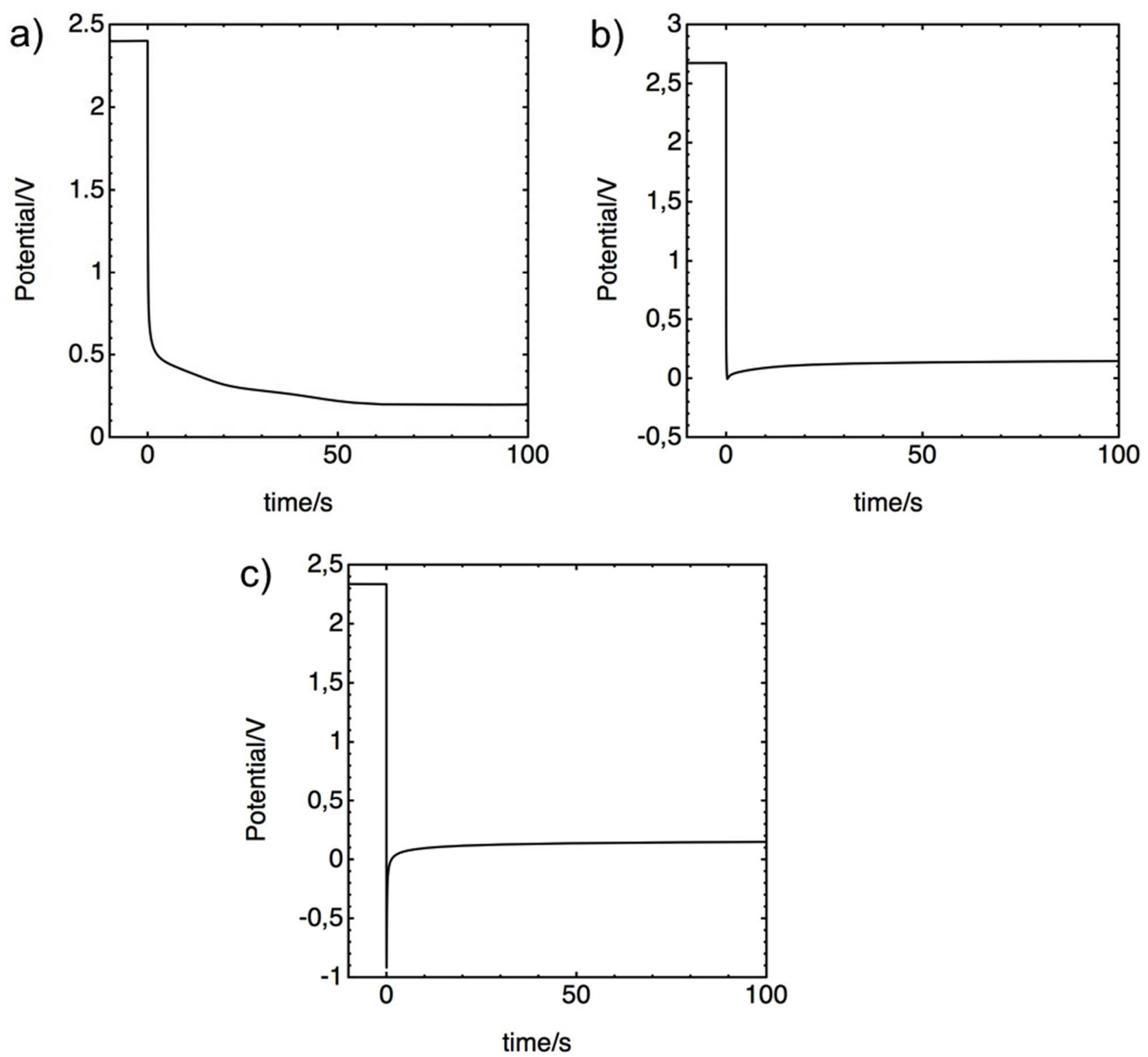

Fig. S1. Potential variation at the beginning of the first lithiation: (a) a-Si:H, 100-nm- thick layer, (b) a-Si ${ }_{0.9}\left(\mathrm{CH}_{3}\right)_{0.1}: \mathrm{H}, 100$-nm- thick layer. (c) a-Si ${ }_{0.9}\left(\mathrm{CH}_{3}\right)_{0.1}: \mathrm{H}, 200$-nm- thick layer. Current density is $\sim 30 \mu \mathrm{A} \mathrm{cm}^{-2}$ in all cases. 


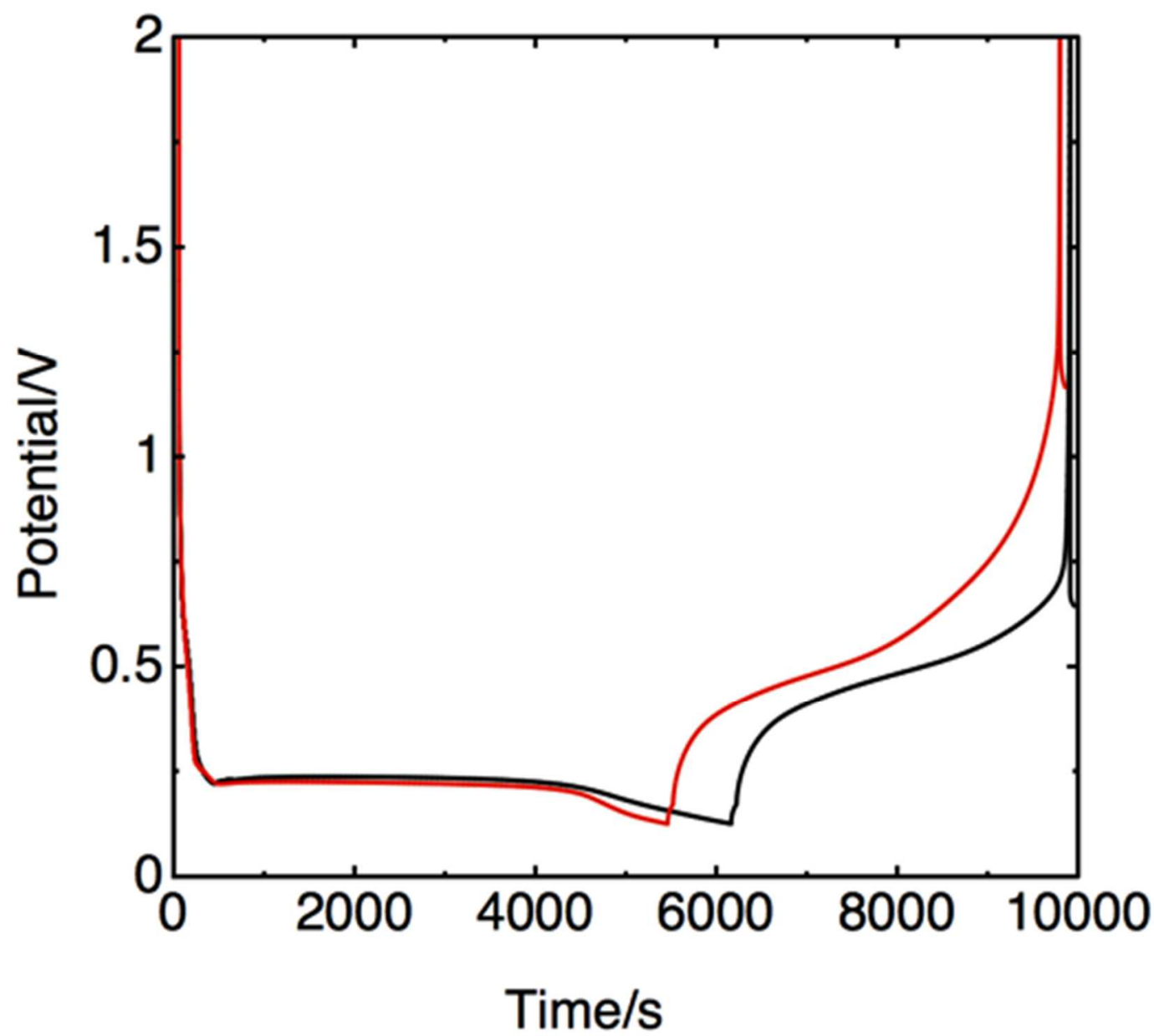

Fig. S2. Comparison of the potential recorded for two 100-nm-thick a-Si:H samples deposited on either a c-Si substrate (black curve) or a polished stainless steel substrate (red curve) during the first cycle. The current density is $\sim 30 \mu \mathrm{A} \mathrm{cm}^{-2}$ in both cases. There are some slight quantitative differences between the two graphs: the capacity and Coulombic efficiency of the layer deposited on $\mathrm{c}-\mathrm{Si}$ are lower than those of the polished stainless steel. This might come from differences between the two layers deposited in two distinct runs with different preparation conditions. Basically, however, a similar behavior is observed for both substrates, with a lithiation plateau close to $200 \mathrm{mV}$. 


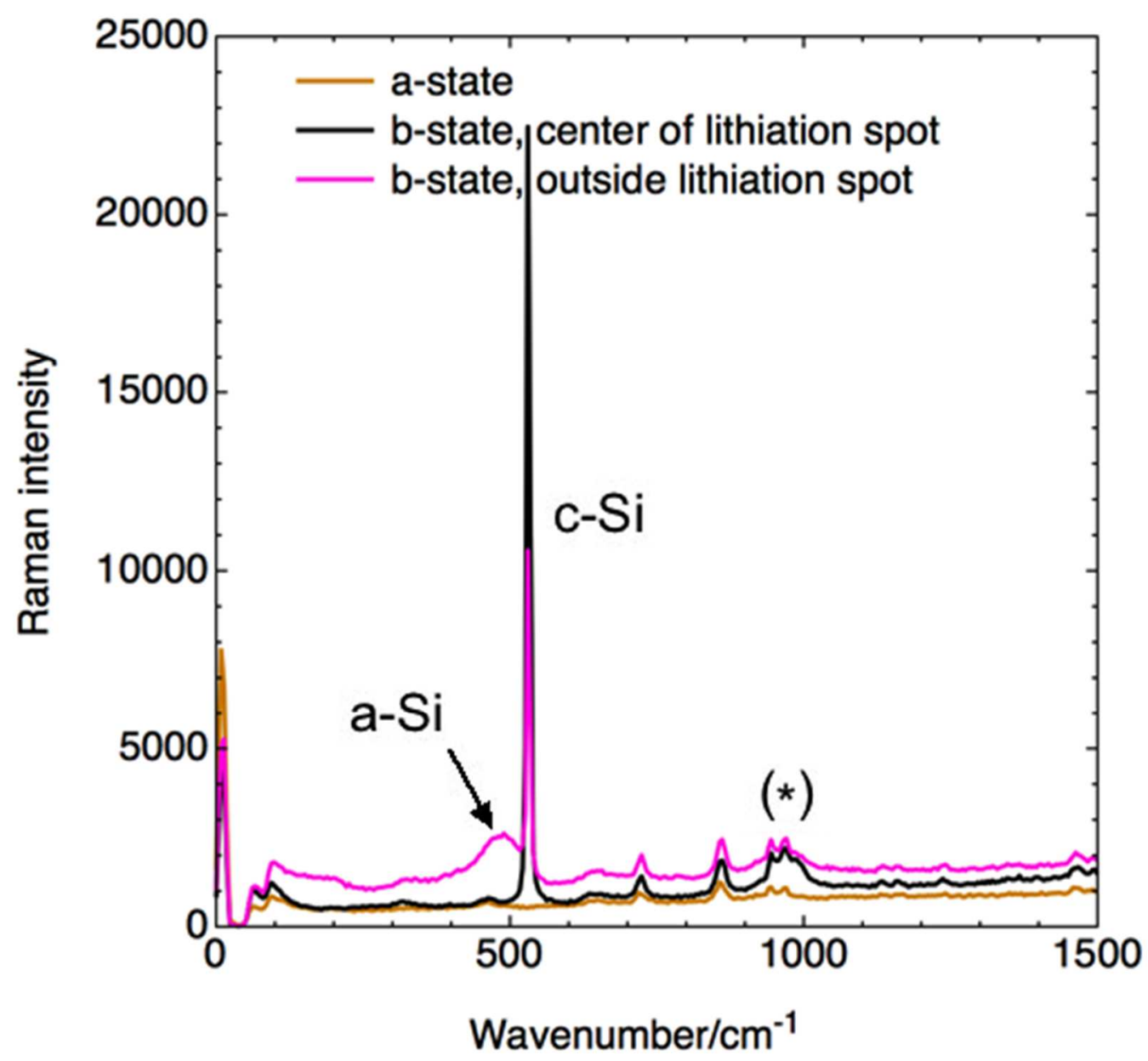

Fig. S3. Raman spectra (excitation wavelength at $470 \mathrm{~nm}$ ) of a 100-nm- thick methylated a$\mathrm{Si}_{0 . .9}\left(\mathrm{CH}_{3}\right)_{0.1}: \mathrm{H}$ layer (sample shown in Fig.5). Spectra were recorded at the center of one lithiation spot before air exposure (a-state, brown line, probed area $2.09 \mu \mathrm{m}^{2}$ ), and after air exposure and EtOH rinsing (b-state, black line, probed area $0.579 \mu \mathrm{m}^{2}$ ). The broad band marked by a (*) which appears in the b-state, is ascribed to oxidation of the material inside the lithiated spot due to air and EtOH exposure. The spectrum of the non-lithiated surface (area outside the lithiation spots), after air exposure is plotted in pink.

After lithiation and before air exposure, a disappearance of the peaks assigned to a-Si $\left(\sim 490 \mathrm{~cm}^{-1}\right)$ and c-Si $\left(\sim 520 \mathrm{~cm}^{-1}\right)$ is observed indicating the formation of an "opaque" lithiated layer. After air exposure and rinsing, the spectrum shows the loss of the broad peak corresponding to a-Si and the re-appearance of the c-Si peak. The enhanced intensity of the later indicates that the layer becomes optically transparent. The change of the optical properties of the lithiated spot very likely indicate a modification of the chemical composition upon air exposure and rinsing. 